Journal of Computer Science 7 (6): 937-940, 2011

ISSN 1549-3636

(C) 2011 Science Publications

\title{
Evaluation of Critical Clearing Time of Power System Equipped With a Series FACT Devices
}

\author{
Prechanon Kumkratug \\ Department of Electrical Engineering, Faculty of Engineering at Si Racha, \\ Kasetsart University, 199 M.6, Tungsukhla, Si Racha, Chonburi, 20230, Thailand
}

\begin{abstract}
Problem statement: The critical clearing time provides very important role of the robustness in power system. The Static Synchronous Series Compensator (SSSC) has been accepted to be equipped in series with modern power system. This study presents the method to evaluate the Critical Clearing Time (CCT) of the system equipped with a SSSC. Approach: The parameter on SSSC is modeled in energy function. The presented energy function is applied to determine CCT of the system. The verification of the proposed method is tested on sample system. Results: The maximum generator rotor angle of the faulted system without a SSSC is continuously oscillation and the maximum value is much more than the system with a SSSC. Conclusion: SSSC based the proposed nonlinear control can damp power system oscillation.
\end{abstract}

Key words: Critical clearing time, power system stability, FACTS devices, energy function, voltage injection, voltage source, short circuit, power engineers, power system

\section{INTRODUCTION}

Now, power engineers are much more concerned about stability problem due to the complicated network of power system. A number of Flexible AC Transmission System (FACTS) controllers, based on the rapid development of power electronics technology, have been proposed for power flow control in steady state and dynamic state. (Chen, 2011; Kouzou et al., 2010; Kumkratug, 2010a; Omar et al., 2010; Zhihuan, et al., 2010; Osuwa and Igwiro, 2010). They have proposed many methods to improve stability of power system such as load shedding, High Voltage Direct Current (HVDC), Flexible AC Transmission system (FACTS), etc (Al-Husban, 2009; Barbuy et al., 2009; Hannan et al., 2009; Kumkratug, 2010b; Mohammadi-Ivatloo, 2009; Sahoo, et al., 2010; Zarate-Minano et al., 2010).

The Static Synchronous Series Compensator (SSSC) can electrically mimic reactor and capacitor by injecting a shunt current in quadrature with the line voltage. The reactive power (or current) of the SSSC can be adjusted by controlling the magnitude and phase angle of the output voltage of the shunt converter (AlHusban, 2009; Kumkratug, 2011)

One of the most important parts of transient stability is to estimate the Critical Clearing Time (CCT). Many previous researches present CCT improvement of power system with FACTS devices by using time domain simulation. To asset the CCT by using time domain simulation method, it is time consuming process because it requires numerous of scenarios of the fault occurrence A Static Synchronous Series Compensator (SSSC) is a member of the FACTS family that is connected in 1 shunt with power system. The SSSC consists of a solid state voltage source converter with GTO thyristor switches or other high performance of semi-conductor and transformer.

This study proposes the energy function of a power system with a SSSC. The CCT of the system with a SSSC is estimated from the proposed energy function and it is compared with the time domain simulation method. In addition, this study will further develop control strategy of the SSSC.

\section{MATERIALS AND METHODS}

Mathematical Model: The dynamics of the generator, without the SSSC, can be expressed by the following differential equations 1 and 2 :

$\dot{\delta}=\omega$

$\dot{\omega}=\frac{1}{\mathrm{M}}\left[\mathrm{P}_{\mathrm{m}}-\mathrm{P}_{\mathrm{e}}^{\mathrm{s}}\right]$

Here $\delta, \omega, \mathrm{P}_{\mathrm{m}}$ and $\mathrm{M}$ are the rotor angle, speed, input mechanical power and moment of inertia, respectively, of the generator. $\mathrm{P}_{\mathrm{e}}^{\mathrm{s}}$ is output electrical power of generator with the SSSC. 


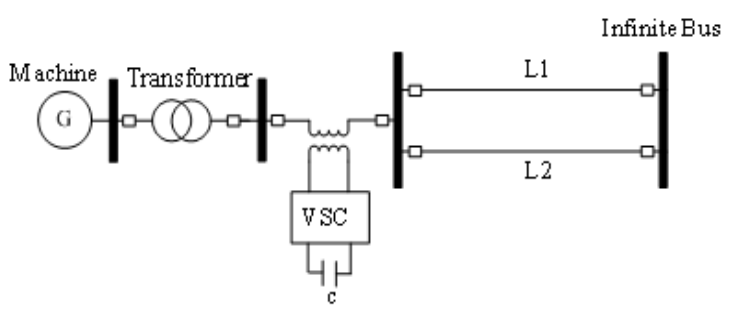

(a)

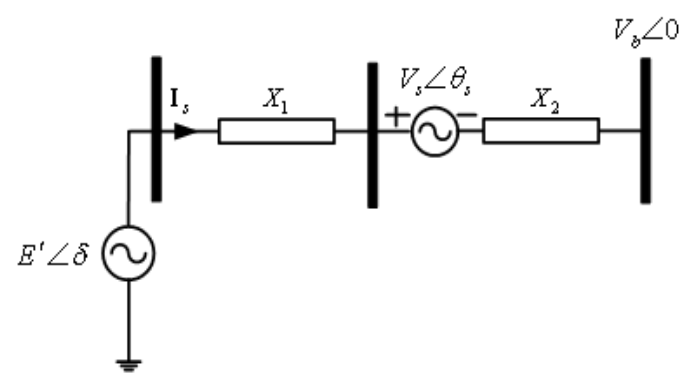

(b)

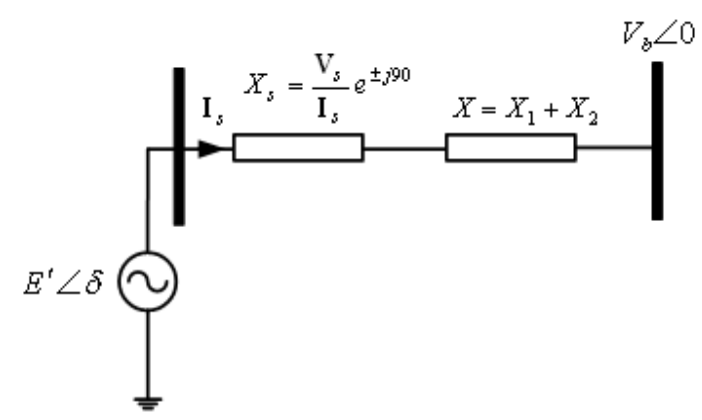

(c)

Fig. 1: Single machine infinite bus system with a SSSC (a) Single line diagram (b) Equivalent circuit of a system with a SSSC represented by a series injected voltage (c) Equivalent circuit of a system with a SSSC represented by a variable reactance

From Fig. 1a, the general equation of the current can be written as Eq. 3:

$$
\mathbf{I}_{\mathrm{s}}=\frac{\mathbf{E}^{\prime}-\mathbf{V}_{\mathrm{s}}-\mathbf{V}_{\mathrm{b}}}{\mathrm{jX}}=\left[\frac{\mathbf{E}^{\prime}-\mathbf{V}_{\mathrm{b}}}{\mathrm{jX}}\right]+\left[\frac{-\mathbf{V}_{\mathrm{s}}}{\mathrm{jX}}\right]=\mathbf{I}_{0}+\Delta \mathbf{I}
$$

Hİere $\Delta \mathbf{I}$ is an additional term because of the SSSC voltage $\left(\mathrm{V}_{\mathrm{s}}\right)$.

A SSSC, limited by its voltage and current ratings, is capable of emulating a compensating reactance, $\mathrm{X}_{\mathrm{s}}$ (both inductive and capacitive in series with the transmission line Eq. 4:

$$
X_{\mathrm{s}}=\frac{\mathbf{V}_{\mathrm{s}}}{\mathbf{I}_{\mathrm{s}}} \mathrm{e}^{ \pm \mathrm{j} 90}
$$

The output electrical power of a Power system with a SSSC $\left(P_{e}^{s}\right)$ is given by Eq. 5 :

$\mathrm{P}_{\mathrm{e}}^{\mathrm{s}}=\frac{\mathrm{E}^{\prime} \mathrm{V}_{\mathrm{b}}}{\mathrm{X}-\mathrm{X}_{\mathrm{s}}} \sin \delta$

Energy Function: The energy function (V) of a power system with a SSSC in Eq. 6:

$\mathrm{V}(\delta, \omega)=\mathrm{V}_{\mathrm{k}}(\omega)+\mathrm{V}_{\mathrm{p}}(\delta)+\mathrm{V}_{\mathrm{c}}(\delta)$

Here $V_{k}$ is kinetic energy, $V_{p}$ is the potential energy of the system a SSSC and $V_{c}$ is the constant energy at the post fault equilibrium point of machine angle $\left(\delta_{\mathrm{s}}\right)$ and speed $\left(\omega_{\mathrm{s}}\right)$. The first integral of the motion of (1), (2) and (5) constitutes a energy function given by:

$$
\mathrm{V}(\delta, \omega)=\left[\int_{0}^{\omega} \mathrm{M} \omega \mathrm{d} \omega\right]-\left[\int_{\delta_{\mathrm{s}}}^{\delta}\left(-\mathrm{Pm}+\mathrm{P}_{\mathrm{e}}^{\mathrm{s}}\right) \mathrm{d} \delta\right]
$$

From (5), the (7) can be written as:

$$
\mathrm{V}(\delta, \omega)=\left[\int_{0}^{\omega} \mathrm{M} \omega \mathrm{d} \omega\right]+\left[\int_{\delta_{\mathrm{s}}}^{\delta}\left[-\mathrm{P}_{\mathrm{m}}+\frac{\mathrm{E}^{\prime} \mathrm{V}_{\mathrm{b}}}{\mathrm{X}-\mathrm{X}_{\mathrm{s}}} \sin \delta\right] \mathrm{d} \delta\right]
$$

From (8), the energy function (V) of a power system with a SSSC is given by Eq. 9:

$$
\mathrm{V}(\delta, \omega)=\left[\frac{1}{2} \mathrm{M} \omega^{2}\right]+\left[-\mathrm{P}_{\mathrm{m}} \delta-\frac{\mathrm{E}^{\prime} \mathrm{V}_{\mathrm{b}}}{\mathrm{X}-\mathrm{X}_{\mathrm{s}}} \cos \delta\right]+\left[\mathrm{V}_{\mathrm{c}}\right]
$$

The first bracket represents the kinetic energy $\left(V_{k}\right)$, the second bracket represents the potential energy $\left(\mathrm{V}_{\mathrm{p}}\right)$ with a SSSC and the third bracket represents the proposed potential energy function $V_{p}$ of SSSC given by:

$\mathrm{V}_{\mathrm{p}}=\left[-\mathrm{P}_{\mathrm{m}} \delta-\frac{\mathrm{E}^{\prime} \mathrm{V}_{\mathrm{b}}}{\mathrm{X}-\mathrm{X}_{\mathrm{s}}} \cos \delta\right]+\left[\mathrm{V}_{\mathrm{c}}\right]$

(10)

Figure 2 shows variation of $\mathrm{V}_{\mathrm{p}}$ against $\delta$. Suppose that the system with a SSSC is subjected to severe disturbance. With $\mathrm{Vs}_{\mathrm{s}}=0$ machine angle will increase from prefault stable equilibrium point $\left(\delta_{0}\right)$ to any 


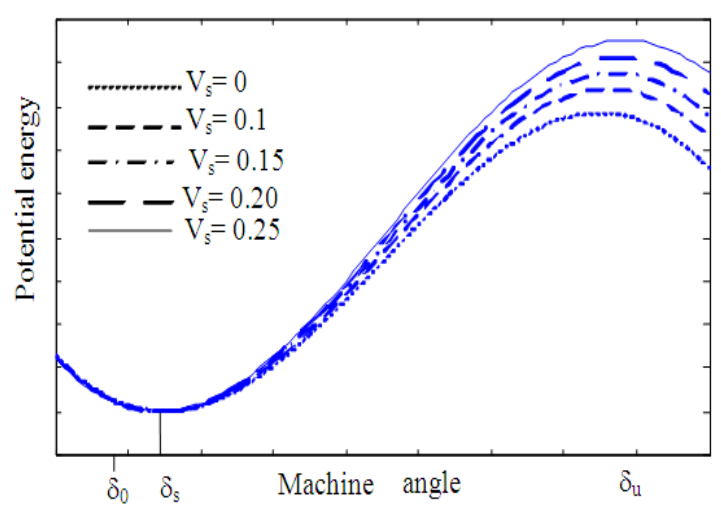

Fig. 2: Energy function against machine angle with various cases

machine angle $\left(\delta>\delta_{\mathrm{s}}>\delta_{0}\right)$ corresponding the potential gets increase. If machine angle reaches at the unstable equilibrium point $\left(\delta_{=} \delta_{u}\right)$ the potential energy function has the maximum value. The system is considered as unstable when $\delta>\delta_{\mathrm{u}}$ and $\mathrm{V}_{\mathrm{p}}(\delta)<\mathrm{V}_{\mathrm{p}}\left(\delta_{\mathrm{u}}\right)$. It can be seen from the figure that the maximum potential energy and unstable equilibrium point gets increase as the $V_{s}$ is increased.

\section{RESULTS}

The proposed control energy function and control strategy of a power system with a SSSC is tested on system of Fig. 1a. It is considered that a three-phase self-clearing type fault appears at bus $\mathrm{m}$. For the critical clearing time (CCT) assessment, this study used the Potential-Energy Boundary Surface (PEBS) method. Fig. 3(a) shows variation curve of the total energy (V) and potential energy $\left(\mathrm{V}_{\mathrm{p}}\right)$ for the system without a $\operatorname{SSSC}\left(\mathrm{V}_{\mathrm{s}}=0\right)$. Figure $3 \mathrm{~b}$ shows variation curve of the total energy $(\mathrm{V})$ and potential energy $\left(\mathrm{V}_{\mathrm{p}}\right)$ for the system with a $\operatorname{SSSC}\left(\mathrm{V}_{\mathrm{s}}=0.1\right)$. Table 1 summarizes the CCT of the system with various rating of a SSSC.

\section{DISCUSSION}

It is shown in Fig. 3 (a) that the maximum value of the $\mathrm{V}_{\mathrm{p}}$ and CCT are around $1.37 \mathrm{pu}$ and $590 \mathrm{msec}$, respectively. However, with $\mathrm{Vs}=0.1 \mathrm{pu}$, the maximum value of $\mathrm{V}_{\mathrm{p}}$ and CCT are increased to $1.54 \mathrm{pu}$ and 608 msec, respectively. With $\mathrm{Vs}_{\mathrm{s}}=0.25$, the maximum value of the $\mathrm{V}_{\mathrm{p}}$ and CCT are increased to 1.70 and $633 \mathrm{msec}$, respectively because the $V_{s}$ increases the potential energy $\mathrm{V}_{\mathrm{p}}^{\text {sh }}$.

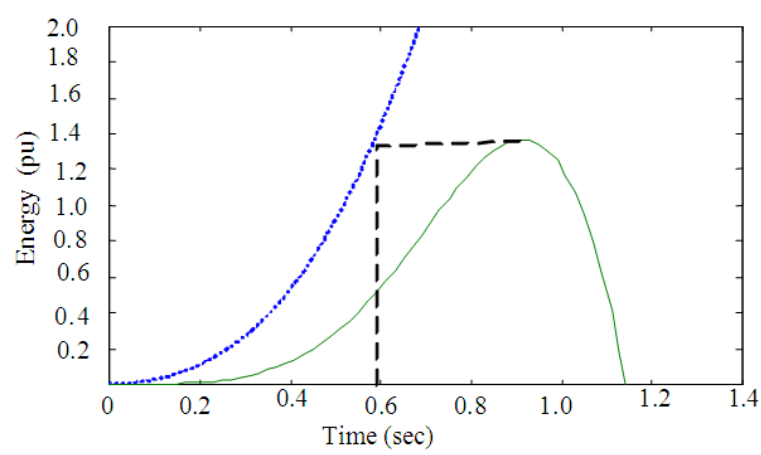

(a)

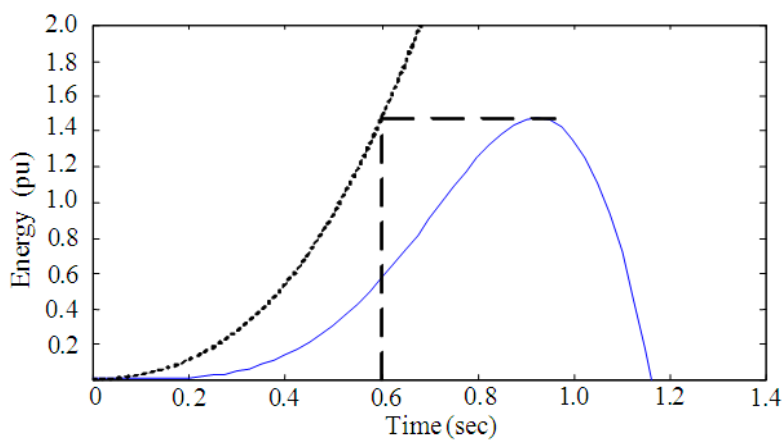

(b)

Fig. 3: Variation of energy function of a power system (a) without SSSC (b) with a SSSC

Table 1: Improvement of $V_{p}$ and $\delta_{u}$ for various cases of SSSC

\begin{tabular}{llll}
\hline $\mathrm{Vs}(\mathrm{pu})$ & $\mathrm{V}_{\mathrm{p}}(\mathrm{pu})$ & $\delta_{\mathrm{u}}($ degree $)$ & $\mathrm{CCT}(\mathrm{msec})$ \\
\hline 0 & 1.37 & 150.00 & $590-591$ \\
0.1 & 1.54 & 151.35 & $608-609$ \\
0.15 & 1.62 & 152.12 & $618-619$ \\
0.20 & 1.71 & 152.67 & $630-631$ \\
0.25 & 1.70 & 154.36 & $633-634$ \\
\hline
\end{tabular}

CONCLUSION

This study presents the method to evaluate the Critical Clearing Time (CCT) of the system equipped with a Static Synchronous Series Compensator (SSSC). The proposed energy function is used to estimate the CCT. The parameter of the SSSC is modeled in the potential energy of a power system. It was found that the SSSC can improve stability of the power system because it can increase the maximum the potential energy and unstable equilibrium point. This study developed the control strategy of the SSSC. The maximum of rating is used for the first swing and nonlinear is used for damping improvement. The proposed energy function is then tested on the simple system and it was found that the SSSC can increase the potential energy and CCT. 


\section{REFERENCES}

Al-Husban, A.N., 2009. An eigenstructure assignment for a static synchronous compensator. Am. J. Eng. Applied Sci., 2: $\quad 812-816 . \quad$ DOI: 10.3844/ajeassp.2009.812.816

Chen, G., 2011. Dynamic optimal power flow in FSWGs integrated power system. Inform. Technol. J., 10: 385-393.

Hannan, M.A., A. Mohamed, A. Hussian and M. Dabbay, 2009. Development of the unified seriesshunt compensator for power quality mitigation. Am. J. Applied Sci., 6: 978-986. DOI: 10.3844/ajassp.2009.978.986

Kouzou, A., M.O. Mahmoudi and M.S. Boucherit, 2010. Apparent power ratio of the shunt active power filter under balanced power system voltages. Asian J. Applied Sci., 3: 363-382.

Kumkratug, P., 2010a. Application of interline power flow controller to increase transient stability of power system. J. Comput. Sci., 6: 1490-1493. DOI: 10.3844/jcssp.2010.1490.1493

Kumkratug, P., 2010b. Fast decoupled power flow for power system with high voltage direct current transmission line system. Am. J. Applied Sci., 7: 1115-1117. DOI: 10.3844/ajassp.2010.1115.1117

Kumkratug, P., 2011. Evaluation of critical clearing time of power system equipped with a static synchronous compensator. Am. J. Applied Sci., 8: 141-146. DOI: 10.3844/ajassp.2011.141.146
Mohammadi-Ivatloo, B., 2009. Optimal placement of PMUs for power system observability using topology based formulated algorithms. J. Applied Sci., 9: 2463-2468.

Omar, R., N.A. Rahim and M. Sulaiman, 2010. New control technique applied in dynamic voltage restorer for voltage sag mitigation. Am. J. Applied Sci., 3: 42-48. DOI: 10.3844/ajeassp.2010.42.48

Osuwa, J.C. and E.C. Igwiro, 2010. Uninterruptible power supply using solar rechargeable battery. Phy. Int., 1: 77-82. DOI: 10.3844/pisp.2010.77.82

Sahoo, A.K., S.S. Dash and T. Thyagarajan, 2010. Power flow study including FACTS devices. J. Applied Sci., 10: 1563-1571.

Zarate-Minano, R., T.V. Custsem, F. Milano and A.J. Conejo, 2010. Securing transient stability using time-domain simulations within an optimal power flow. IEEE Trans. Power Syst., 25: 243-253. DOI: 10.1109/TPWRS.2009.2030369

Zhihuan, L., L. Yinhong and D. Xianzhong, 2010. Improved strength pareto evolutionary algorithm with local search strategies for optimal reactive power flow. Inform. Technol. J. http://docsdrive.com/pdfs/ansinet/itj/0000/1767917679.pdf 